\title{
Validation of a new prognostic index score for disseminated nasopharyngeal carcinoma
}

\author{
C-K Toh', D Heng', Y-K Ong', S-S Leong', J Wee ${ }^{3}$ and E-H Tan ${ }^{*, 1}$ \\ 'Department of Medical Oncology, National Cancer Centre, II Hospital Drive, Singapore 1696 I0, Singapore; ${ }^{2}$ Clinical Trials and Epidemiology Research \\ Unit, Singapore Health Services Pte Ltd, I I Third Hospital Avenue, Singapore I6875 I, Singapore; ${ }^{3}$ Department of Therapeutic Radiology, National \\ Cancer Centre, II Hospital Drive, Singapore 169610, Singapore
}

Patients with metastatic nasopharyngeal carcinoma have variable survival outcomes. We previously designed a scoring system to better prognosticate these patients. Here, we report results on validation of this new prognostic index score in a separate cohort of patients. Clinical features and laboratory parameters were examined in 172 patients with univariate and multivariate analyses and a numerical score was derived for each independent prognostic variable. Significant independent prognostic variables and their scores assigned included poor performance status (score 5), haemoglobin $<12 \mathrm{~g} \mathrm{dl}^{-1}$ (score 4) and disease-free interval (DFI) (DFI $\leqslant 6$ months (score 10) or metastases at initial diagnosis (score I)). Maximum score was 19 and patients stratified into three prognostic groups: good, 0-3; intermediate, 4-8; poor, $\geqslant 9$. When applied to a separate cohort of 120 patients, 59 patients were good, 43 intermediate and I 8 poor prognosis, with median survivals of 19.6 (95\% Cl I 6.I , 23.1), I 4.3 (95\% Cl I2.3, I6.2) and 7.9 (95\% Cl 6.6, 9.2) months, respectively. (logrank test: $P=0.003$ ). We have validated a new prognostic score with factors readily available in the clinics. This simple score will prove useful as a method to prognosticate and stratify patients as well as to promote consistent reporting among clinical trials.

British Journal of Cancer (2005) 92, I 382 - | 387. doi:I0.1038/sj.bjc.6602525 www.bjcancer.com

Published online 5 April 2005

(c) 2005 Cancer Research UK

Keywords: nasopharyngeal carcinoma; prognostic factors; metastatic survival

Nasopharyngeal carcinoma (NPC) occurs sporadically in the West but constitute a major health problem in several parts of Asia, including Southern China, Hong Kong and Singapore (Parkin, 2001). In Singapore, the incidence rate in Chinese is among the highest in Asia and the disease ranks as the fifth most common cancer among Chinese males (Chia et al, 2000). The histological pattern of NPC among the Chinese population comprise mainly the World Health Organization (WHO) types II (nonkeratinising) and III (undifferentiated) (Chan et al, 1998). Both histological types are often considered together as they share similar epidemiological, clinical and serologic characteristics, as distinct from the epidermoid carcinoma of the head and neck region seen in the western population (Shanmugaratnam and Sobin, 1993; Altun et al, 1995).

There is a high incidence of distant metastases with nonkeratinising or undifferentiated NPC, as compared to other epidermoid carcinoma arising in the head and neck region (Reddy et al, 1995). This is especially true for patients who present with locally advanced disease (Ahmad and Stefani, 1986). A prospective study showed a high rate of subclinical distant metastasis, with a distinctive feature of bone marrow invasion (Micheau et al, 1987). In addition, the incidence of distant failure after radiotherapy treatment for locally advanced disease can be as high as $57 \%$ in $\mathrm{N}_{3}$

*Correspondence: Dr E-H Tan; E-mail: dmoteh@nccs.com.sg Received 2 December 2004; revised 17 February 2005; accepted 17 February 2005; published online 5 April 2005 disease (Lee et al, 1992). In view of the high rate of systemic relapse, chemotherapy has been incorporated into the primary treatment of locally advanced disease in order to improve the outcome. Concurrent chemoradiotherapy was shown to improve overall and progression-free survival for locally advanced NPC in the Intergroup study (Al-Sarraf et al, 1998) and this was replicated in studies carried out in the endemic areas of Singapore (Wee et al, 2004), Hong Kong (Lee et al, 2004) and Taiwan (Lin et al, 2003). However, a significant proportion of patients would still relapse systemically despite combined modality therapy and many of these patients would ultimately succumb to disseminated disease.

Patients with disseminated disease do not behave in a uniform manner. It is hence not surprising to see significantly variable results between studies of similar therapeutic manoeuvres in patients with metastatic NPC. We have shown in our previous study that by using several clinical and laboratory parameters, we were able to define three prognostically distinct groups of patients with disseminated NPC (Ong et al, 2003). We proposed that a prognostic index scoring system using these parameters could be used for a more accurate prognostic evaluation of a patient. However more importantly, it can also be used for a more accurate stratification of patients in prospective clinical studies and hopefully help to standardise reporting results of any therapeutic interventions.

We now report a follow-on study that reanalysed our previous findings to define a new prognostic index score and to validate this new score in a separate cohort of patients with disseminated NPC. 


\section{PATIENTS AND METHODS}

\section{Patients}

All patients were treated at the Department of Medical Oncology, National Cancer Centre between January 1994 and January 2003. There were two different cohorts of patients: the first (Cohort 1) was the group on which the new prognostic index score was derived and included 220 patients treated between January 1994 and December 1999, while the second cohort (Cohort 2) was the group on which the new score was validated. Cohort 2 included 99 patients treated between January 2002 and January 2003 and 21 patients (not included in our previous analysis for Cohort 1) from a previous Institutional Review Board-approved phase II clinical trial conducted in 1996 (Au et al, 1998).

All patients had a histological confirmation of NPC and had computerised tomography (CT) scan of the posterior nasal space, chest X-ray and/or CT scan of the thorax, ultrasound or CT scan of the abdomen and bone radionuclide scan to identify the extent of systemic disease. Patients were classified into the International Union Against Cancer/American Joint Committee on Cancer (UICC/AJCC) stages using the clinical and radiological data.

Pretreatment patient and disease characteristics, disease-free interval (DFI) (time from the onset of primary radiotherapy or chemoradiotherapy to the time of distant relapse), type of chemotherapy given, best response to chemotherapy, type of salvage chemotherapy given and date of death were recorded for all patients.

\section{Survival data}

The primary end point of interest was metastatic survival. Metastatic survival was defined as survival subsequent to the development of distant relapse, that is, from the first diagnosis of distant metastases to the time of death. Locoregional recurrence was not considered a distant relapse. The survival status of all patients was verified with Singapore's national death registry for Cohorts 1 and 2 as on 30 June 2000 and 31 December 2003, respectively. The cohorts excluded patients who were nonresidents of Singapore and as notification is mandatory in the event of death, the mortality data obtained from the death registry was complete and exhaustive.

\section{Statistical analysis}

The analysis to derive a new prognostic score was performed on Cohort 1 and focused only on 172 patients who had received chemotherapy. The original prognostic index score was based on all patients including patients who were not treated with chemotherapy (Ong et al, 2003). As chemotherapy has an impact on survival outcome in patients with disseminated disease, there was a need to rederive a new prognostic index score using only patients from Cohort 1 who received palliative chemotherapy as all the patients from Cohort 2 were treated with chemotherapy. Univariate and multivariable analyses were performed using the Cox proportion hazards model. The multivariable analyses were undertaken with both forward and backward stepwise procedures for identifying the independent prognostic variables. Factors that were considered in the derivation of the new prognostic index score included age, gender, performance status according to Eastern Co-operative Oncology Group (ECOG) criteria, specific metastatic sites, number of metastatic sites, metastasis at presentation, stage at first diagnosis, DFI, leucocyte count, haemoglobin $(\mathrm{Hb})$ level, and albumin level, on the basis of our previous analysis. In order to construct the new prognostic index score, factors were entered as categorical values as far as possible to keep the computations simple, although categorisation inevitably will result in some loss of information. $P \leqslant 0.05$ was used as the cutoff value of statistical significance for variable selection in the multivariable modelling. The regression coefficient of each independent prognostic variable (the $\beta$ in the Cox regression equation hazard ratio $(\mathrm{HR})=\mathrm{e}^{\beta}$ ) is then modified into an integer numerical value to construct the new prognostic index score. The patients were stratified, based on the new prognostic index score, into three different risk groups with significantly different median metastatic survivals.

The validation of the new prognostic index score was subsequently performed on Cohort 2 patients. Overall and median metastatic survival estimates and curves were obtained using the Kaplan-Meier method and logrank test was used to compare among the three prognostic groups stratified by the new score.

\section{RESULTS}

\section{Patient and disease characteristics (Table 1)}

Table 1 shows the characteristics of patients in both cohorts who had received at least one line of palliative chemotherapy at diagnosis of distant metastases. All patients had nonkeratinising or undifferentiated NPC. There was a male predominance in both cohorts. Most characteristics were similar between both cohorts. The median age at diagnosis of metastases was 47 years for Cohort 1 and 48 years for Cohort 2. In all, 35 (20.3\%) patients in Cohort 1 and $27(22.5 \%)$ patients in Cohort 2 had metastases at diagnosis. The majority had distant relapse after treatment for locally advanced disease previously. Bone was the most common site of metastasis, followed by liver, lung and distal nodes. Most of the patients had multiple sites involved at diagnosis of metastases.

The proportion of patients with good ECOG status of 0 and 1 was higher in Cohort 2 (95.8\%) compared to Cohort $1(87.8 \%)$ $(P=0.07)$. Several chemotherapy regimens were used in the firstline setting and these included Cisplatin and Fluorouracil, Paclitaxel and Gemcitabine either alone or in combination with Carboplatin.

\section{Survival distribution}

Patients from Cohort 2 appeared to have better survival, although this was not statistically significant (logrank test $P$-value $=0.07$ ). See Figure 1. The median metastatic survival for patients in Cohort 1 was 12.9 months (95\% CI 10.5,15.3) and that for patients in Cohort 2 was 15.6 months (95\% CI 13.2, 18.0). The 1-, 2- and 3year survival proportions were 52, 25 and $10 \%$ for Cohort 1 and 66, 33 and $15 \%$ for Cohort 2, respectively.

\section{Univariate and multivariate analysis}

The univariate analysis was performed on the 172 patients who were treated with chemotherapy in Cohort 1 . Factors considered in the univariate analyses were based on our previous study and included age, gender, performance status, laboratory parameters such as $\mathrm{Hb}$, leucocyte count and albumin level, stage at first diagnosis, sites and number of metastases and DFI. The factors associated with an adverse prognosis were anaemia $\left(\mathrm{Hb}<12 \mathrm{~g} \mathrm{dl}^{-1}\right)$, ECOG $\geqslant 2, \mathrm{DFI} \leqslant 6$ months, presence of multiple metastases and liver metastases. See Table 2.

The variables included in the multivariate analysis were similar to that used in the univariate analysis. Using a significance level of 0.05 , the significant independent variables were $\mathrm{Hb}$ level $\left(\mathrm{Hb}<12 \mathrm{~g} \mathrm{dl}^{-1}\right.$ with HR: 2.1$)$, performance status (ECOG $\geqslant 2$ with HR: 2.6), DFI (metastasis at diagnosis and short DFI with HR: 1.2 and 7.7 respectively). See Table 3 . These three variables predicted negatively for metastatic survival. 
Table I Patient and disease characteristics

\begin{tabular}{|c|c|c|c|c|c|}
\hline \multirow[b]{2}{*}{ Characteristics } & \multicolumn{2}{|c|}{ Cohort I } & \multicolumn{2}{|c|}{ Cohort 2} & \multirow[b]{2}{*}{$P$-value } \\
\hline & $\begin{array}{c}\text { No. of } \\
\text { patients }\end{array}$ & $\%$ & $\begin{array}{l}\text { No. of } \\
\text { patients }\end{array}$ & $\%$ & \\
\hline No. of patients & 172 & & 120 & & \\
\hline Survival status & & & & & $\begin{array}{c}\text { See } \\
\text { logrank } \\
\text { test }\end{array}$ \\
\hline Dead & 130 & 75.6 & 91 & 75.8 & \\
\hline Alive & 42 & 24.4 & 29 & 24.2 & \\
\hline Age, in years & & & & & $<0.001$ \\
\hline $\begin{array}{l}\text { Median } \\
\text { Interquartile range }\end{array}$ & $\begin{array}{r}47 \\
(40,54)\end{array}$ & & $\begin{array}{r}48 \\
(42,54)\end{array}$ & & \\
\hline Gender & & & & & 0.32 \\
\hline Male & 144 & 83.7 & 95 & 79.2 & \\
\hline Female & 28 & 16.3 & 25 & 20.8 & \\
\hline ECOG status ${ }^{a}$ & & & & & 0.07 \\
\hline 0 & 18 & 10.5 & 19 & 15.8 & \\
\hline I & 133 & 77.3 & 96 & 80 & \\
\hline 2 & 14 & 8.1 & 2 & 1.7 & \\
\hline 3 & 6 & 3.5 & 3 & 2.5 & \\
\hline 4 & I & 0.6 & 0 & 0 & \\
\hline \multicolumn{6}{|l|}{ Laboratory parameters } \\
\hline Albumin $\left(\mathrm{g}^{-1}\right)$ & & & & & 0.38 \\
\hline$<40$ & 128 & 74.4 & 90 & 75 & \\
\hline$\geqslant 40$ & 32 & 18.6 & 29 & 24.1 & \\
\hline Hemoglobin $\left(\left.g\right|^{-1}\right)$ & & & & & 0.003 \\
\hline$<12$ & 106 & 61.6 & 54 & 45 & \\
\hline$\geqslant 12$ & 63 & 36.6 & 66 & 55 & \\
\hline UICC/AJCC stage at first diagnosis ${ }^{b}$ & & & & & 0.002 \\
\hline I & 5 & 2.9 & 2 & 1.7 & \\
\hline$\| A$ & I & 0.6 & 4 & 3.3 & \\
\hline$\| B$ & 31 & 18 & 4 & 3.3 & \\
\hline III & 39 & 22.7 & 39 & 32.5 & \\
\hline IVA & 20 & 11.6 & 16 & 13.3 & \\
\hline IVB & 27 & 15.7 & 16 & 13.3 & \\
\hline IVC & 33 & 19.2 & 27 & 22.5 & \\
\hline Disease-free interval & & & & & 0.16 \\
\hline Mets at diagnosis & 35 & 20.3 & 27 & 22.5 & \\
\hline$\leqslant 6$ months & 11 & 6.4 & 15 & 12.5 & \\
\hline$>6$ month & 125 & 72.7 & 78 & 65 & \\
\hline \multicolumn{6}{|l|}{ Sites of metastasis } \\
\hline Bone & 118 & 68.6 & 79 & 65.8 & 0.26 \\
\hline Liver & 74 & 43 & 63 & 52.5 & 0.12 \\
\hline Lung & 65 & 37.8 & 51 & 42.5 & 0.41 \\
\hline Distant nodes & 63 & 36.6 & 39 & 32.5 & 0.43 \\
\hline No. of metastatic sites & & & & & 0.3 \\
\hline Single & 69 & 40.1 & 41 & 34.2 & \\
\hline Multiple & 103 & 59.9 & 79 & 65.8 & \\
\hline Prior chemotherapy before mets & & & & & 0.58 \\
\hline Yes & 14 & 8.1 & 12 & 10 & \\
\hline No & 158 & 91.9 & 108 & 90 & \\
\hline Salvage chemotherapy & & & & & 0.02 \\
\hline Yes & 91 & 52.9 & 68 & 61.8 & \\
\hline No & 81 & 47.1 & 42 & 38.2 & \\
\hline
\end{tabular}

${ }^{a}$ ECOG status refers to performance status as defined by the Eastern Cooperative Oncology Group. 'bICCIAJCC refers to International Union against Cancer/ American Joint Committee on Cancer.

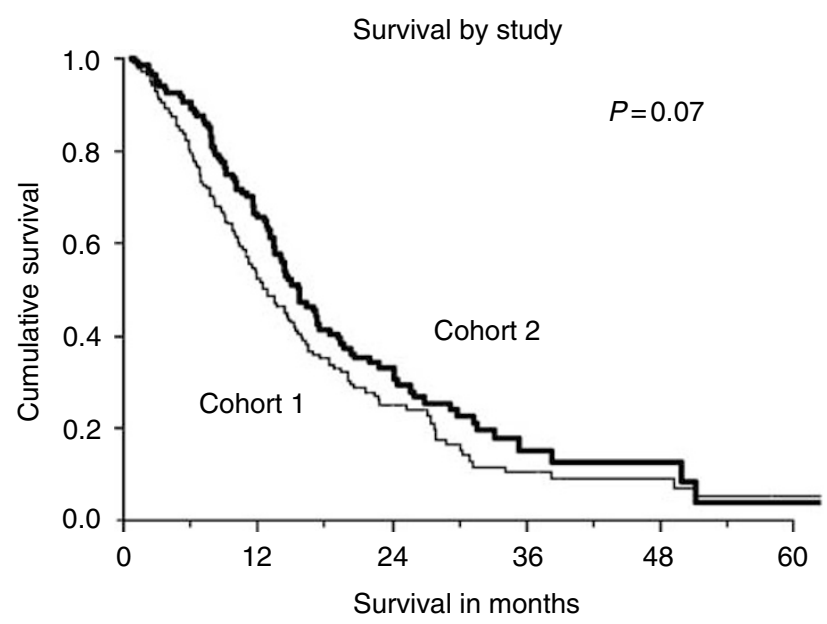

Figure I Survival curves for Cohorts I and 2. There is no statistically significant difference in metastatic survival between the two cohorts.

\section{New prognostic index score and risk groups}

A numerical score was derived from the regression coefficient of each of the three independent prognostic variables derived above, namely, anaemia $\left(\mathrm{Hb}<12 \mathrm{~g} \mathrm{dl}^{-1}\right), \mathrm{ECOG} \geqslant 2$ and DFI. A score of 0 was assigned if the factor was absent or $1,4,5$ or 10 according to the factor present. See Table 4. The new prognostic index score for each individual patient was calculated by adding up the scores of each independent factor. The maximum score obtainable was 19, instead of 20 as metastasis at diagnosis and short DFI were mutually exclusive. In view of the gaps between the scores, the possible scores were $0-1,4-6,9-11,14-16$ and 19 . The patients were stratified into three prognostic groups based on the new prognostic index score: 57 patients in the low-risk group (score: $0-3$ ), 86 patients in intermediate-risk group (score: $4-8$ ) and 25 patients in high-risk group (score: $\geqslant 9$ ). The median metastatic survivals for the three different risk groups were 25.3 (95\% CI 17.7-33.9), 11.7 (95\% CI 9.9-13.6) and 5.8 (95\% CI 5.0-6.5) months, respectively. (logrank test, $P<0.0001$ ). See Figure 2.

\section{Validation of new prognostic index score}

The new prognostic index score was applied to the patients in Cohort 2. The proportion of patients in the low-risk, intermediaterisk and high-risk groups were 49,36 and $15 \%$, respectively. The median metastatic survivals of these three different groups were as follows: 19.6 (95\% CI 16.1-23.1), 14.3 (95\% CI 12.3-16.2) and 7.9 (95\% CI 6.6-9.2) months respectively (logrank, $P=0.003$ ). See Figure 3.

\section{DISCUSSION}

We previously presented our results on derivation of a prognostic index score derived from all patients in Cohort 1 that included those not treated with chemotherapy (Ong et al, 2003). However, as Cohort 2 was used for validation of the score and all the patients in Cohort 2 were treated, we elected to reanalyse Cohort 1 to restrict the derivation of a new prognostic index score to only patients given chemotherapy. The reason for the reanalysis is that chemotherapy has an impact on survival outcome in patients with disseminated NPC, although there are no randomised comparison studies between chemotherapy and best supportive care (Fandi et al, 1994; Hong et al, 1999). This is also supported by the fact that incorporation of chemotherapy in locally advanced disease has been shown to improve progression-free and overall survival 
Table 2 Univariate analysis of patients treated with chemotherapy in Cohort I $(N=172)$

\begin{tabular}{|c|c|c|c|c|}
\hline Factor & $\begin{array}{c}\text { No. of } \\
\text { patients }\end{array}$ & $\begin{array}{l}\text { No. } \\
\text { alive }\end{array}$ & $\begin{array}{l}\text { Hazard ratio } \\
(95 \% \mathrm{Cl})\end{array}$ & $P$-value \\
\hline \multicolumn{5}{|l|}{ Gender } \\
\hline Female & 28 & 6 & Baseline & \\
\hline Male & 144 & 36 & $0.66(0.41-1.04)$ & 0.075 \\
\hline \multicolumn{5}{|l|}{ Age, in years } \\
\hline$\leqslant 54$ & 78 & 23 & Baseline & \\
\hline $46-65$ & 84 & 16 & $1.31(0.92-1.88)$ & 0.14 \\
\hline$>65$ & 10 & 3 & $1.79(0.81-3.96)$ & 0.15 \\
\hline \multicolumn{5}{|l|}{ Albumin, $g l^{-1}$} \\
\hline$\geqslant 04$ & 32 & 10 & Baseline & \\
\hline$<40$ & 128 & 31 & $1.43(0.89-1.88)$ & 0.13 \\
\hline \multicolumn{5}{|l|}{ Haemoglobin, $\mathrm{g} \mathrm{dl}^{-1}$} \\
\hline$\geqslant 12^{\circ}$ & 63 & 28 & Baseline & \\
\hline$<12$ & 106 & 14 & $2.61(1.76-3.87)$ & $<0.001$ \\
\hline \multicolumn{5}{|l|}{ ECOG status ${ }^{\mathrm{a}}$} \\
\hline $0-1$ & $15 \mid$ & 41 & Baseline & \\
\hline 2 & 14 & 1 & $2.24(1.26-4.00)$ & 0.006 \\
\hline $3-4$ & 7 & 0 & $4.19(1.93-9.18)$ & $<0.001$ \\
\hline \multicolumn{5}{|l|}{ Leucocyte count, $\times 10^{9} \mathrm{I}^{-1}$} \\
\hline$<4$ & 26 & 4 & Baseline & \\
\hline $4-11$ & 112 & 35 & $0.77(0.48-1.24)$ & 0.29 \\
\hline$>11$ & 31 & 3 & $1.46(0.83-2.56)$ & 0.19 \\
\hline \multicolumn{5}{|l|}{$\begin{array}{l}\text { UICC/AJCC stage at first } \\
\text { diagnosis }^{b}\end{array}$} \\
\hline $\mid-\|$ & 37 & 8 & Baseline & \\
\hline$|I|-\mid V B$ & 86 & 23 & $1.21(0.78-1.89)$ & 0.38 \\
\hline IVC & 33 & 9 & $1.41(0.81-2.45)$ & 0.22 \\
\hline \multicolumn{5}{|l|}{ Bone metastasis } \\
\hline No & 42 & 10 & Baseline & \\
\hline Yes & 118 & 27 & $1.24(0.82-1.85)$ & 0.3 \\
\hline \multicolumn{5}{|l|}{ Liver metastasis } \\
\hline No & 97 & 26 & Baseline & \\
\hline Yes & 74 & 16 & $1.60(1.13-2.28)$ & 0.008 \\
\hline \multicolumn{5}{|l|}{ Lung metastasis } \\
\hline No & 106 & 27 & Baseline & \\
\hline Yes & 65 & 15 & $1.19(0.83-1.70)$ & 0.35 \\
\hline \multicolumn{5}{|l|}{ Distal node metastasis } \\
\hline No & 107 & 19 & Baseline & \\
\hline Yes & 63 & 22 & $0.81(0.56-1.18)$ & 0.27 \\
\hline \multicolumn{5}{|l|}{ Number of metastatic sites } \\
\hline Single & 69 & 17 & Baseline & \\
\hline Multiple & 103 & 25 & $1.55(1.08-2.21)$ & 0.017 \\
\hline \multicolumn{5}{|l|}{ Disease-free interval } \\
\hline$>6$ months & 125 & 32 & Baseline & \\
\hline$\leqslant 6$ months & 11 & 1 & $4.03(2.02-8.02)$ & $<0.001$ \\
\hline Metastases at diagnosis & 35 & 9 & $1.25(0.81-1.94)$ & 0.31 \\
\hline
\end{tabular}

aECOG status refers to performance status as defined by the Eastern Cooperative Oncology Group. 'UICCIAJCC refers to International Union against Cancer/ American Joint Committee on Cancer.

(Al-Sarraf et al, 1998; Lin et al, 2003; Wee et al, 2004). Thus, with reanalysis, we have eliminated the bias with the use of chemotherapy and make the two cohorts more comparable.

We found that DFI, Hb level $\left(<12 \mathrm{~g} \mathrm{dl}^{-1}\right)$ and poor performance status $(E C O G \geqslant 2)$ were significant negative prognostic factors in patients treated with chemotherapy and these three independent
Table 3 Significant independent variables from multivariate analysis for patients treated with chemotherapy in Cohort I $(N=172)$

\begin{tabular}{lcc}
\hline Factor & Hazard ratio $\mathbf{( 9 5 \%} \mathbf{C l})$ & P-value \\
\hline Haemoglobin level $\left(<12 \mathrm{~g} \mathrm{dl}^{-1}\right)$ & $2.067(1.34-3.17)$ & 0.001 \\
Performance status $\left(\mathrm{ECOG} \geqslant 2^{\mathrm{a}}\right)$ & $2.585(1.45-4.59)$ & 0.001 \\
Disease-free interval & $1.21(0.75-1.95)$ & 0.031 \\
$\quad$ Metastasis at diagnosis & $7.656(2.23-26.25)$ & \\
$\quad \leqslant 6$ months &
\end{tabular}

${ }^{a}$ ECOG refers to performance status as defined by the Eastern Cooperative Oncology Group.

Table 4 New prognostic index score and risk groups

\begin{tabular}{lcc}
\hline Factor & Score & $\boldsymbol{\beta}\left(\text { hazard ratio }=\mathbf{e}^{\boldsymbol{\beta}}\right)^{\mathbf{a}}$ \\
\hline Haemoglobin level $\left(<12 \mathrm{~g} \mathrm{dl}{ }^{-1}\right)$ & 4 & 0.73 \\
Performance status $\left(\mathrm{ECOG} \geqslant 2^{\mathrm{b}}\right)$ & 5 & 0.95 \\
Disease-free interval & & \\
$\quad$ Metastasis at diagnosis & 1 & 0.19 \\
$\quad \leqslant 6$ months & 10 & 2.04 \\
Maximum score & 19 &
\end{tabular}

Low risk: score $0-3$; intermediate risk: score $4-8$; high risk: score $\geqslant 9$. ${ }^{a} \beta=$ Regression Coefficient. ${ }^{b}$ ECOG refers to performance status as defined by the Eastern Cooperative Oncology Group.

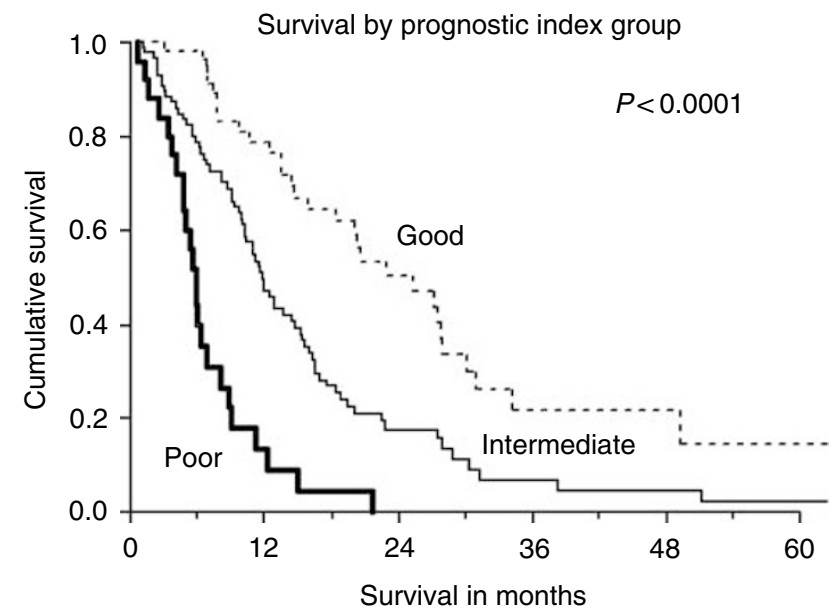

Figure 2 Survival by new prognostic index grouping derived from patients in Cohort I. There is a clear demarcation of survival differences between the three risk groups.

variables were used in the derivation of the new prognostic index score. Metastasis at diagnosis and short DFI were regarded as two separate categories within the same DFI variable and thus were mutually exclusive. The natural history of a disease is dependent on the interaction of both patient and disease factors. Anaemia can be related to the disease process itself, host-related factors or treatment given and has been shown to be associated with significant reduction in survival in various cancers, other than NPC (Caro et al, 2001; Bokemeyer et al, 2002). Anaemia may reflect not only a biologically more aggressive tumour but may be a mediating factor to resistance to treatment and this has been demonstrated in retrospective studies on cervical cancer treated with chemoradiation (Obermair et al, 2001). The negative prognostic factor of a poor performance status has been shown in many other tumour types as well (Paesmans et al, 1995; Polee 


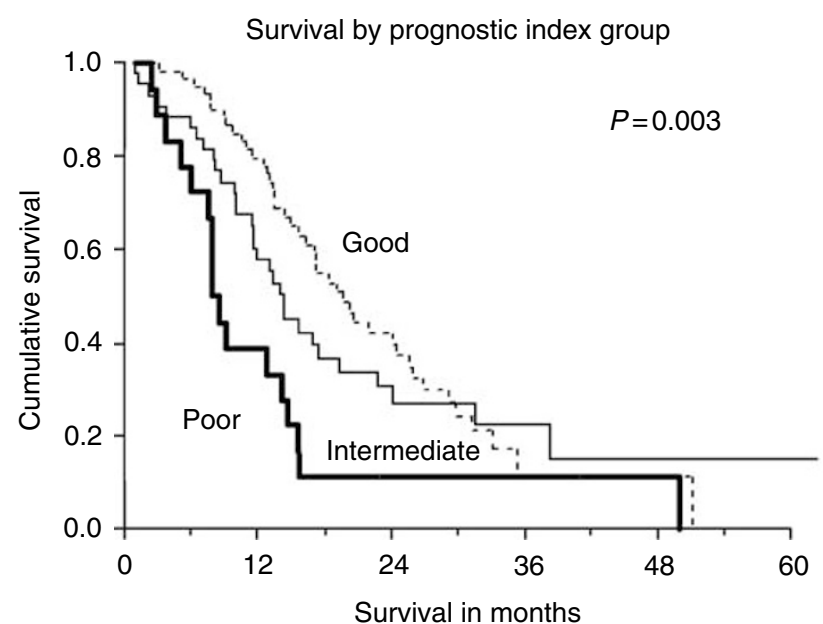

Figure 3 Survival by new prognostic index grouping applied to patients in Cohort 2. There is a statistically significant difference between the three risk groups.

et al, 2003; Motzer et al, 2004). Patients with poor performance status do not tolerate treatment well and it may also be a reflection of the more advanced state of the cancer.

Patients who present with metastasis at diagnosis can be a result of delay in seeking medical attention or more likely, a reflection of the aggressive nature of the disease such that it is widespread by the time the patient becomes symptomatic. Having a short DFI is also reflective of an aggressive disease and has been convincingly shown to portend a poorer outcome in other tumours such as ovarian cancer (Markman et al, 1991). Our analysis showed that a short DFI after initial radiotherapy or chemoradiotherapy for the primary tumour had a worse prognostic score compared to metastasis at diagnosis and this is likely due to emerging chemoresistant clones within the tumour of those patients who relapse shortly after treatment.

A study by Teo et al (1996) showed that short DFI, the presence of liver metastasis and age at diagnosis were prognostic for metastatic survival in metastatic NPC. Short DFI is included as a factor in our new prognostic index score but the other two variables were found to be not statistically significant on multivariate analysis. This may be a result of our population of patients being limited to only those treated with chemotherapy and the treatment likely negated the prognostic significance of age and site of metastasis. Statistical issues, such as variations in modelling procedure in small to moderate size data sets between the different studies, could be an alternative explanation.

The metastatic survival of patients with disseminated NPC treated with chemotherapy is highly variable and our findings provide further supportive evidence for that. In Cohort 1, at the time of analysis in June 2000, the metastatic survival varied from 1 to 72 months. Similarly, for Cohort 2, the metastatic survival duration varied from 1 month to 103 months: 10 patients died within 3 months of diagnosis of metastatic disease despite chemotherapy, while 13 patients are still alive after 2 years. In fact, one patient survived 8 years 7 months while another three lived beyond 4 years after diagnosis of metastatic disease. A number of studies have reported similar findings, with several long-term survivors with the use of chemotherapy in metastatic NPC (Chan et al, 1997; Fandi et al, 2000). Based on the results of our studies, it is possible for single-arm studies or randomised studies that are inadequately powered or stratified to report spuriously improved survival outcome with a new therapeutic intervention because of biased patient selection alone. As a result of this heterogeneity, it is imperative that a method be developed to better prognosticate and stratify patients for more accurate assessment of efficacy of any new therapeutic interventions.

It is important to note that the new prognostic index score resulted in clear demarcation of three prognostically different groups with nonoverlapping confidence intervals of the median survival durations and this demarcation was replicated in the separate cohort of patients. Another important point to note is that the new prognostic index score incorporates clinical data that are used in routine patient care in most institutions.

There is accumulating evidence for the use of biomarkers in the detection and prognostication of NPC. The biomarkers include circulating markers in the blood, such as Epstein-Barr virus (EBV) DNA (Chien et al, 2001) and CYFRA 21-1 (Ma et al, 2004), as well as tumour immunohistochemical markers such as the expression of multidrug-resistance protein (Hsu et al, 2002), epidermal growth factor receptors (Chua et al, 2004) and signal transducers and activators of transcription factors (Hsiao et al, 2003). Among them, plasma EBV DNA has been the most validated and has been shown to be a predictor of poor survival after radiotherapy for local disease (Chan et al, 2002). However, these biomarkers are not readily available in most institutions and they are yet to be validated as prognostic factors in the metastatic setting.

It is conceivable that similar prognostic classifications can be designed and used for other disseminated solid tumours as well, for instance breast or colorectal cancers. Such a prognostic classification based on combination of patient and laboratory factors may be able to categorise patients with disseminated disease more accurately as shown in NPC in this study and hence will be useful for stratifying patients in randomised studies.

We have validated a new prognostic index score in metastatic NPC patients treated with chemotherapy. This new prognostic index score can stratify patients into three different prognostic groups with significantly different median metastatic survivals. This prognostic classification system will be useful for more accurate prognostication of patients with disseminated NPC. In addition, it can prove useful in the design of clinical trials for metastatic NPC as it can more accurately stratify patients into groups with fairly consistent outcome and thus make the results more comparable and interpretable.

\section{ACKNOWLEDGEMENTS}

This work was presented in part at the 40th annual meeting of the American Society of Clinical Oncology, 5-8 June 2004, New Orleans, LA, USA. The authors have no disclosures of financial interests to declare.

\section{REFERENCES}

Ahmad A, Stefani S (1986) Distant metastases of nasopharyngeal carcinoma: a study of 256 male patients. J Surg Oncol 33: 194-197

Al-Sarraf M, LeBlanc M, Giri PGS, Fu KK, Cooper J, Vuong T, Forastiere AA, Adams G, Sakr WA, Schuller DE, Ensley JF (1998) Chemoradiotherapy versus radiotherapy in patients with advanced nasopharyngeal cancer: phase III randomised intergroup study 0099. J Clin Oncol 16: $1310-1317$

Altun M, Fandi A, Dupuis O, Cvitkovic E, Kranjina Z, Eschwege F (1995) Undifferentiated nasopharyngeal cancer (UCNT): current diagnostic and therapeutic aspects. Int J Radiat Oncol Biol Phys 32: 859-877 
Au E, Tan EH, Ang PT (1998) Activity of paclitaxel by three-hour infusion in Asian patients with metastatic undifferentiated nasopharyngeal cancer. Ann Oncol 9: 327-329

Bokemeyer C, Oechsle K, Hartmann JT, Schoffski P, Schleucher N, Metzner B, Schleicher J, Kanz L (2002) Treatment-induced anaemia and its potential clinical impact in patients receiving sequential high dose chemotherapy for metastatic testicular cancer. Br J Cancer 87: 1066 - 1071

Caro JJ, Salas M, Ward A, Goss G (2001) Anaemia as an independent prognostic factor for survival in patients with cancer: a systematic, quantitative review. Cancer 91: 2214-2221

Chan AT, Lo YM, Zee B, Chan LY, Ma BB, Leung SF, Mo F, Lai M, Ho S, Huang DP, Johnson PJ (2002) Plama Epstein-Barr virus DNA and residual disease after radiotherapy for undifferentiated nasopharyngeal carcinoma. J Natl Cancer Inst 94: 1614-1619

Chan AT, Teo ML, Lee WY, Kwan WH, Choi PH, Johnson PJ (1998) The significance of keratinising squamous cell histology in Chinese patients with nasopharyngeal carcinoma. Clin Oncol (R Coll Radiol) 10: 161-164

Chan ATC, Teo PML, Leung TWT, Johnson PJ (1997) The role of chemotherapy in management of nasopharyngeal carcinoma. Cancer 82: $1003-1012$

Chia KS, Seow A, Lee H P, Shanmugaratnam K (2000) Cancer incidence in Singapore 1993 - 1997: Singapore Cancer Registry Report No. 5

Chien YC, Chen JY, Liu MY, Yang HI, Hsu MM, Chen CJ, Yang CS (2001) Serologic markers of Epstein-Barr virus infection and nasopharyngeal carcinoma in Taiwanese men. $N$ Engl J Med 345: 1877-1882

Chua DT, Nicholls JM, Sham JS, Au GK (2004) Prognostic value of epidermal growth factor receptor expression in patients with advanced stage nasopharyngeal carcinoma treated with induction chemotherapy and radiotherapy. Int J Radiat Oncol Biol Phys 59: 11-20

Fandi A, Altun M, Azli N, Armand JP, Cvitkovic E (1994) Nasopharyngeal cancer: epidemiology, staging, and treatment. Semin oncol 21: 382-397

Fandi A, Bachouchi M, Azli N, Taamma A, Boussen H, Wibault P, Eschwege F, Armand JP, Simon J, Cvitkovic E (2000) Long-term disease-free survivors in metastatic undifferentiated carcinoma of nasopharyngeal type. J Clin Oncol 18: $1324-1330$

Hong RL, Sheen TS, Ko JY, Hsu MM, Wang CC, Ting LL (1999) Induction with mitomycin $\mathrm{C}$, doxorubicin, cisplatin and maintenance with weekly 5-fluorouracil, leucovorin for treatment of metastatic nasopharyngeal carcinoma: a phase II study. Br J Cancer 80: $1962-1967$

Hsiao JR, Jin YT, Tsai ST, Shiau AL, Wu CL, Su WC (2003) Constitutive activation of STAT3 and STAT5 is present in the majority of nasopharyngeal carcinoma and correlate with better prognosis. $\mathrm{Br} J$ Cancer 89: $344-349$

Hsu CH, Chen CL, Hong RL, Chen KL, Lin JF, Cheng AL (2002) Prognostic value of multidrug resistance 1 , glutathione-S-transferase-pi and p53 in advanced nasopharyngeal carcinoma treated with systemic chemotherapy. Oncology 62: 305-312

Lee AW, Lau WH, Tung SY, Chua D, Chappell R, Siu L, Chia S, Lau J, Law SCK (2004) Prospective randomised study on therapeutic gain achieved by addition of chemotherapy for T1-4N2-3M0 nasopharyngeal carcinoma (NPC). J Clin Oncol 22: 489 (suppl; abstr. 5506)

Lee AWM, Poon YF, Foo W, Law SCK, Cheung FK, Chan DKK, Tung SY, Thaw M, Ho JHC (1992) Retrospective analysis of 5037 patients with nasopharyngeal carcinoma treated during 1976-1985: overall survival and patterns of failure. Int J Radiat Oncol Phys 23: 261-270
Lin J, Jan J, Hsu C, Liang W, Jiang R, Wang W (2003) Phase III study of concurrent chemoradiotherapy versus radiotherapy alone for advanced nasopharyngeal carcinoma: positive effect on overall and progressionfree survival. J Clin Oncol 21: 631-637

Ma BBY, Leungm SF, Hui EP, Mo F, Kwan WH, Zee B, Yuen J, Chan ATC (2004) Prospective validation of serum CYFRA 21-1, $\beta$-2-microglobulin, and ferritin levels as prognostic markers in patients with nonmetastatic nasopharyngeal carcinoma undergoing radiotherapy. Cancer 101: $776-781$

Markman M, Rothman R, Hakes T, Reichman B, Hoskins W, Rubin S, Jones W, Almadrones L, Lewis Jr JL (1991) Second-line platinum therapy in patients with ovarian cancer previously treated with cisplatin. J Clin Oncol 9: 389-393

Micheau C, Boussen H, Klijanienko J, Cvitkovic E, Stosic S, Schwabb G, Eschwege F, Armand JP (1987) Bone marrow biopsies in patients with undifferentiated carcinoma of the nasopharyngeal type. Cancer 60: $2459-2464$

Motzer RJ, Bacik J, Schwartz LH, Reuter V, Russo P, Marion S, Mazumdar M (2004) Prognostic factors for survival in previously treated patients with metastatic renal cell carcinoma. J Clin Oncol 22: $454-463$

Obermair A, Cheuk R, Horwood K, Janda M, Bachtiary B, Schwanzelberger B, Stoiber A, Nicklin JL, Perrin LC, Crandon AJ (2001) Impact of hemoglobin levels before and during concurrent chemoradiotherapy on the response of treatment in patients with cervical carcinoma: preliminary results. Cancer 92: 903-908

Ong YK, Heng DM, Chung B, Leong SS, Wee J, Fong KW, Tan T, Tan EH (2003) Design of a prognostic index score for metastatic nasopharyngeal carcinoma. Eur J Cancer 39: 1535-1541

Paesmans M, Sculier JP, Libert P, Bureau G, Dabouis G, Thiriaux J, Michel J, Van Cutsem O, Sergysels R, Mommen P (1995) Prognostic factors for survival in advanced non-small cell lung cancer: univariate and multivariate analyses including recursive partitioning and amalgamation algorithms in 1052 patients. J Clin Oncol 13: 1221-1230

Parkin DM (2001) Global cancer statistics in the year 2000. Lancet Oncol 2: 533-543, Erratum in: Lancet Oncol 2: 596.

Polee MB, Hop WCJ, Kok TC, Eskens FALM, van der Burg MEL, Splinter TAW, Siersema PD, Tilanus HW, Stoter G, van der Gaast A (2003) Prognostic factors for survival in patients with advanced oesophageal cancer treated with cisplatin-based combination chemotherapy. $\mathrm{Br} J$ Cancer 89: 2045 - 2050

Reddy SP, Raslan WF, Gooneratne S, Kathuria S, Marks JE (1995) Prognostic significance of keratinisation in nasopharyngeal carcinoma. Am J Otolaryngol 16: $103-108$

Shanmugaratnam K, Sobin LH (1993) The World Health Organisation histological classification of tumours of the upper respiratory tract and ear. Cancer 71: 2689-2697

Teo PM, Kwan WH, Lee WY, Leung SF, Johnson PJ (1996) Prognosticators determining survival subsequent to distant metastasis from nasopharyngeal carcinoma. Cancer 77: 2423-2431

Wee J, Tan EH, Tai BC, wong BH, Leong SS, Tan T, Chua ET, Lee KM, Yang E, Machin D (2004) Phase III randomised trial of radiotherapy versus concurrent chemo-radiotherapy in patients with AJCC/UICC (1997) stage 3 and 4 nasopharyngeal cancer of the endemic variety. J Clin Oncol 22: 488 (suppl; abstr. 5500) 